\title{
A Novel Graphene Oxide Composite Nanofiltration Membrane with Excellent Performance and Antifouling Ability
}

Xiangli Song, Yunfeng Li, Guangjin Zhao, Yingzhou Lu, Chunxi Li and Hong Meng*

College of Chemical Engineering, Beijing University of Chemical Technology, Beijing 100029, China

\begin{abstract}
Graphene Oxide (GO), as a new type of nanomaterial, has been used in a composite Nanofiltration (NF) membrane showing good performance. It was deposited on a polysulfone support membrane modified with dopamine. In order to prepare an NF membrane with good stability, GO was cross-linked with 1,3,5-benzenetricarbonyl trichloride through a layer-by-layer assembly method. The prepared $\mathrm{GO}$ composite NF membrane (M-GO) has been characterized by FTIR, XPS, and SEM. The prepared M-GO showed superior NF performance. The rejection rate and permeation flux of the membrane towards methyl blue were up to $98 \%$ and $70 \mathrm{kgm}-2 \mathrm{~h}-1$, respectively, and the corresponding values towards PO43- were up to $92 \%$ and $120 \mathrm{kgm}-2 \mathrm{~h}-1$, respectively.
\end{abstract}

Keywords: Nanofiltration membrane; Graphene oxide; Dopamine

\section{Introduction}

Nanofiltration (NF) technology is widely applied in industry due to its low energy consumption, environmental benignity, high efficiency, and so on [1,2], especially in water treatment [3-6]. However, traditional NF membranes often have disadvantages of low water flux, weak antifouling ability [7], and poor stability. In order to circumvent these drawbacks associated with traditional NF membranes, it is imperative to select an efficient membrane material. The properties of the chosen material directly affect the separation performance, stability, and antifouling ability of the NF membrane. NF membranes prepared with different materials can be applied to different NF processes.

Recently, the application of dopamine to modify membrane surfaces has attracted widespread attention [8-10]. Researchers found that, in aqueous solution, the catechol moiety of dopamine is very easily oxidized to generate a dopamine quinone compound with an $o$-benzoquinone structure. Under certain conditions, dopamine quinone can react with fresh dopamine to generate a Polydopamine (PDA) composite layer on the surface of the substrate $[11,12]$. Such a polydopamine composite layer is strongly adhered to the matrix while also bearing hydrophilic hydroquinone groups, which provides a new means of improving the hydrophilicity of the membrane [13]. Modified polysulfone ultrafiltration membrane surfaces with dopamine, and the polydopamine-modified membranes showed better hydrophilicity than the unmodified membranes. In addition, dopamine can enable membrane functionalization [14] deposited a polydopamine and PEI mixed functional layer on a PAN ultrafiltration membrane surface, and then introduced zirconia to prepare an organic-inorganic composite NF membrane. The product showed better retention properties for divalent ions deposited polydopamine on the surfaces of a microfiltration membrane, a reverse osmosis membrane, and an ultrafiltration membrane, and then grafted long polyethylene glycol chains with different molecular weights to prepare composite membranes with better anti-fouling abilities [15].

With the development of nanotechnology, GO, as a typical nanomaterial, has been widely used in the field of membrane research and development [16-19]. Compared with traditional membranes, membranes modified with GO show significant advantages in terms of water flux, chemical stability, anti-fouling ability, and mechanical strength [20]. GO is a two-dimensional nanomaterial [21-24], bearing functionalities such as carboxyl, carbonyl, epoxy, and hydroxyl [25-27]. As a result, it is easy to stack to form a separation layer. The mechanism of operation of a GO separation layer with nanopores and a large amount of negative charge is shown in Fig. 1. The separation layer provides size-based rejection between neutral small molecules and charge-based rejection between anions, thus making GO a perfect membrane material deposited GO crosslinked with SG (solvent green) on a ceramic membrane surface modified with dopamine, and found that the prepared SG@GO composite membrane showed a significant improvement in terms of water flux [28]. Wang et al. [29] prepared a polycation/GO NF membrane by the Layer-By-Layer (LBL) assembly method and found that this membrane showed excellent anti-fouling ability (Figure 1).

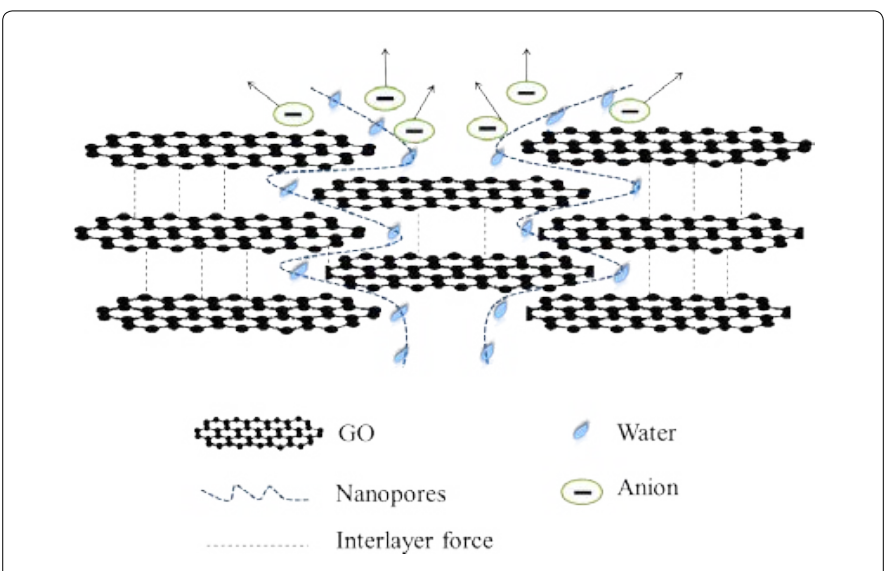

Figure 1: Separation mechanism of the GO membrane.

*Corresponding author: Hong Meng, College of Chemical Engineering, Beijing University of Chemical Technology, Beijing 100029, China, Tel: +00861064410308; E-mail: menghong@mail.buct.edu.cn

Received June 13, 2018; Accepted June 26, 2018; Published July 02, 2018

Citation: Song X, Li Y, Zhao G, Lu Y, Li C, et al. (2018) A Novel Graphene Oxide Composite Nanofiltration Membrane with Excellent Performance and Antifouling Ability. J Membr Sci Technol 8: 184. doi:10.4172/2155-9589.1000184

Copyright: $\odot 2018$ Song X, et al. This is an open-access article distributed under the terms of the Creative Commons Attribution License, which permits unrestricted use, distribution, and reproduction in any medium, provided the original author and source are credited. 
In order to solve the problems of traditional NF membranes showing low ion retention capacity, low water flux, weak pollution resistance, and poor stability, we deposited GO on the surface of a dopamine-modified polysulfone ultrafiltration membrane by the LBL self-assembly method. The GO was then cross-linked with 1,3,5-benzenetricarbonyl trichloride (TMC) to prepare a GO composite NF membrane (M-GO). The experimental process and the corresponding reaction principle are shown in Figure 2. It found that the M-GO displays interesting properties, such as high anion retention capacity, high water flux, good pollution resistance, and good stability. This may be attributed to the following factors: 1) polydopamine formed on the PS (polysulfone) membrane surface showed strong adhesion and strong hydrophilicity; 2) the cross-linking agent (TMC) covalently cross-linked GO, increasing the stability of the GO separation layer; 3 ) the edges of GO bear a large number of hydrophilic groups that can rapidly bind water molecules; the bound water molecules extend through the predominately hydrophobic skeleton of graphene, facilitating the passage of water molecules through the nanopores by the capillary effect [30-33]. In this study, the deposition conditions of M-GO were investigated and appropriate characterization tests were carried out.

\section{Materials and Methods}

GO was purchased from the Chinese Academy of Sciences Chengdu Organic Chemistry Co., Ltd (Chengdu, China). Dopamine (DA, 98\%) was supplied by Ark Pharm, Inc. TMC was obtained from Chemical Technology (Shanghai) Co., Ltd. Isopar L was purchased from Sigma -
Aldrich (Darmstadt, Germany). Flat-sheet PS ultrafiltration membrane was purchased from Sepro Membranes. Methyl blue, Congo red, acid magenta, crystal violet, and methyl orange were all purchased from Shanghai Aladdin Biochemical Technology Co., Ltd. $\mathrm{NaCl}, \mathrm{Na}_{2} \mathrm{SO}_{4}$, and $\mathrm{Na}_{3} \mathrm{PO}_{4}$ were obtained from Beijing Chemical Factory.

\section{Membrane preparation}

(1) A $6 \mathrm{~cm} \times 6 \mathrm{~cm}$ flat-sheet PS membrane was immersed in the volume fraction of $30 \%$ ethanol (ethanol/water $(30: 70, \mathrm{v} / \mathrm{v})$ ) for $30 \mathrm{~min}$, then taken out, quickly rinsed with deionized water, and dried at room temperature.

(2) A solution of dopamine (2 g) was prepared in Tris- $\mathrm{HCl}$ buffer (1 L) and adjusted to $\mathrm{pH} 8.5$.

(3) The treated PS membrane was immersed in the freshly prepared dopamine solution for $1 \mathrm{hr}$, then taken out and quickly rinsed with deionized water to remove unreacted chemical species from its surface, and dried at room temperature. In this way, a dopamine composite membrane (M-PDA) was prepared. Repeating the aforementioned steps yielded a multi-layer dopamine composite membrane M-PDA ${ }^{n}$.

(4) The M-PDA was immersed in a $0.2 \%(w / v)$ TMC solution in Isopar $\mathrm{L}$ for $30 \mathrm{~min}$, then taken out and briefly rinsed with Isopar $\mathrm{L}$ to remove excess TMC. In this way, the composite membrane M-TMC was prepared.

(5) M-TMC was immersed in a $0.5 \mathrm{gL}^{-1} \mathrm{GO}$ solution in Isopar L for

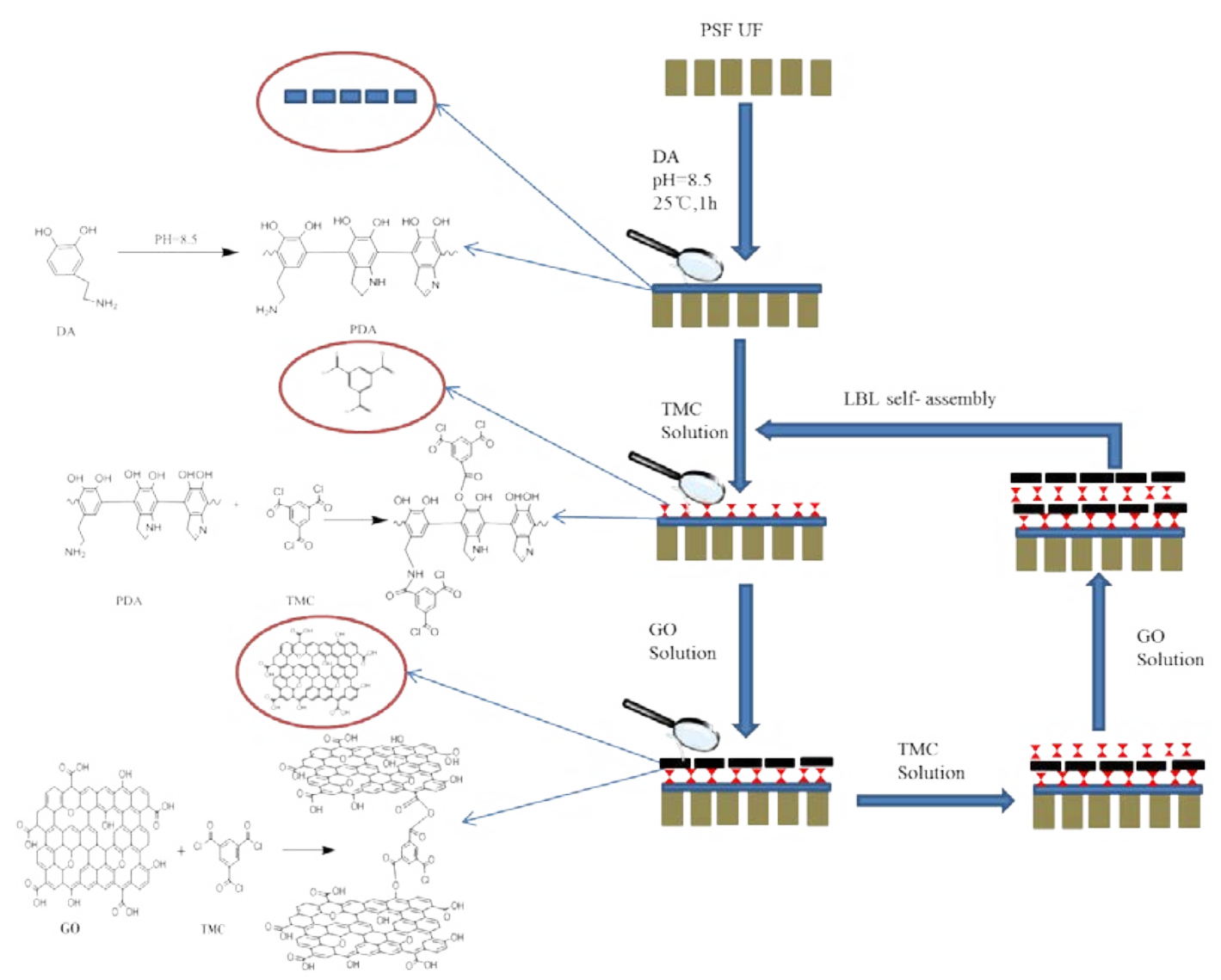

Figure 2: Preparation of M-GO and reaction principles. 
$30 \mathrm{~min}$, then taken out and briefly rinsed with Isopar L to remove excess GO. In this way, the GO composite membrane (M-GO $\left.{ }^{1}\right)$ was prepared.

(6) $\mathrm{M}-\mathrm{GO}^{1}$ was immersed in a water bath at $95^{\circ} \mathrm{C}$ for $2 \mathrm{~h}$ to completely remove any residual Isopar L.

(7) The aforementioned procedure was repeated to prepare $\mathrm{M}-\mathrm{GO}^{n}$ with different numbers of composite layers.

\section{Characterization}

The surface morphologies of PS and composite membranes were characterized by scanning electron microscopy (SEM) (SU-8020, Hitachi, Tokyo, Japan). The change in the elemental composition during the process of preparing composite membranes was tested by X-ray photoelectron spectroscopy (XPS) (ESCALAB 250, HitachiIn order to study the hydrophilicity of the surfaces of the composite membranes, a contact-angle meter (OCA20, Data Physics, Stuttgart, Germany) was used to measure water contact angles thereon.

Attenuated total reflectance FTIR spectra (Vertex 70, Bruker, Karlsruhe, Germany) were recorded to assess the functional group changes of the composite membranes. In order to study the change in surface roughness of the composite membranes, atomic force microscopy (AFM, DMFASTSCAN2-SYS, Karlsruhe, Bruker) was used. Zeta potentials of composite membrane surfaces were measured with a zeta potential meter (Zetasizer 2000, Malvern, Malvern, UK).

\section{Nanofiltration experiments}

The rejection efficiencies and water fluxes of organic dyes (methyl blue, Congo red, acid fuchsin, crystal violet, methyl orange) and anions $\left(\mathrm{Cl}, \mathrm{SO}_{4}^{2-}, \mathrm{PO}_{4}^{3-}\right)$ were measured. The experimental set-up is shown in Figure 3. Firstly, organic dye and salt solutions at certain concentrations were prepared as raw materials. These solutions were pumped into the membrane cell by means of a piston pump, making the raw material liquid flow through the graphene composite membrane surface, whereupon the ions and dye molecules were partially rejected. When the operating pressure was stable, aliquots of the treated solution were collected, recording the operating time and the mass of the treated solution. In this study, the concentrations of ions and organic dyes in the treated solutions were measured by chromatography and UV/Vis spectrophotometry, respectively. Lastly, we calculated the corresponding rejection and flux.

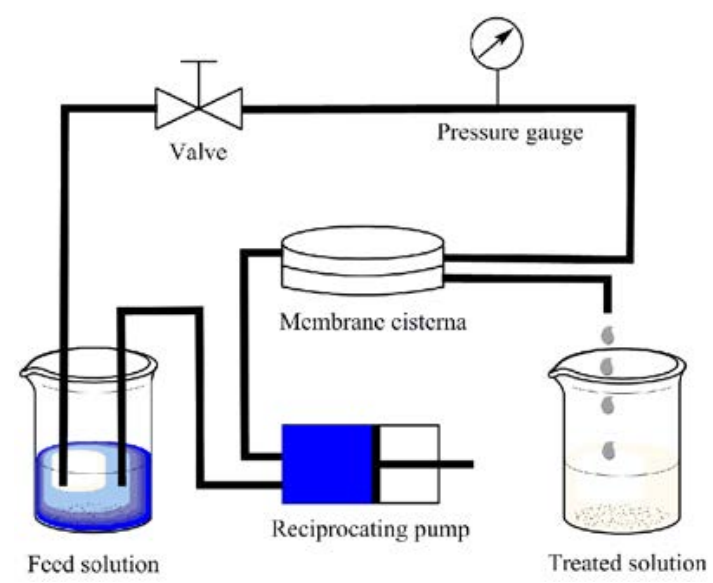

Figure 3: Performance evaluation apparatus for M-GO.
The performance of the M-GO was assessed by checking its rejection and flux. The membrane was subjected to organic dye and ion rejection studies using organic dyes at $100 \mathrm{ppm}$ and $\mathrm{NaCl}, \mathrm{Na}_{2} \mathrm{SO}_{4}$, and $\mathrm{Na}_{3} \mathrm{PO}_{4}$ at $500 \mathrm{ppm}$. All permeation experiments were carried out at a pressure of $0.6 \mathrm{MPa}$, and the effective membrane area was $15.9 \mathrm{~cm}^{2}$. The rejection percentage and flux were calculated using the following equation (1) and (2):

$$
\mathrm{R}(\%)=100 \times\left(1-\left(\mathrm{C}_{\mathrm{p}} / \mathrm{C}_{\mathrm{f}}\right)\right)
$$

Where $\mathrm{R}$ is the rejection rate, and $\mathrm{C}_{\mathrm{p}}(\mathrm{ppm})$ and $\mathrm{C}_{\mathrm{f}}(\mathrm{ppm})$ are the concentrations of permeate and the feed solution, respectively.

$$
\mathrm{F}=\frac{\mathrm{W}}{\mathrm{A} \cdot \mathrm{t}}
$$

Here, $\mathrm{F}\left(\mathrm{kgm}^{-2} \mathrm{~h}-1\right)$ is the permeation flux, $\mathrm{W}(\mathrm{kg})$ is the mass of permeation solution, $A\left(\mathrm{~m}^{2}\right)$ is the effective membrane area, and $t(h)$ is the operation time.

\section{Results and Discussions}

\section{Characterization of the base support and its composite membranes}

In this study, all membranes were characterized, namely the PS membrane, one-layer PDA composite membrane (M-PDA), three-layer PDA composite membrane (M-PDA $\left.{ }^{3}\right), \mathrm{TMC}$ composite membrane

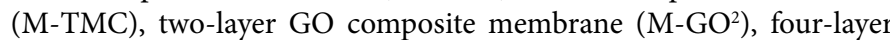
GO composite membrane $\left(\mathrm{M}-\mathrm{GO}^{4}\right)$, and six-layer $\mathrm{GO}$ composite membrane $\left(\mathrm{M}-\mathrm{GO}^{6}\right)$. The preparation conditions of the membranes were as follows: dopamine concentration $2 \mathrm{gL}^{-1}$; TMC concentration 0.2 w t\%; GO concentration $0.5 \mathrm{gL}^{-1}$.

In order to study changes in the surface morphology in the process of preparing GO composite membranes, the surfaces of the PS membrane, M-PDA, and M-GO ${ }^{2}$ were each examined by SEM, the SEM images are shown in Figure 4(a-c). From Figure 4(a), it can be seen that there were numerous holes of diameter around $100 \mathrm{~nm}$ on the surface of the PS membrane. After the deposition of PDA, the diameter of the holes clearly decreased, as shown in Figure 4(b), and it was difficult to observe their distribution. In addition, some particles were sparsely distributed on the M-PDA surface, attributable to the aggregation of PDA. From Figure 4(c), it can be seen that the $\mathrm{M}-\mathrm{GO}^{2}$ surface exhibited a layered sheet structure, attributable to layer-by-layer stacking of GO. Moreover, irregular wrinkles appeared on the $\mathrm{M}-\mathrm{GO}^{2}$ surface, which improved the water flux to some extent, since these increased the contact area between water and the membrane surface [34].

XPS was used to analyze the hybridization of carbon on the surfaces of the PS membrane, M-PDA, and M-GO ${ }^{2}$. XPS images are shown in Figure 5. As can be seen in Figure 5(a,b), the hybridization of the carbon on the PS membrane and M-PDA remained unchanged, with peaks due to $\mathrm{C}-\mathrm{C}\left(\mathrm{sp}^{2}\right)$ at $284.6 \mathrm{eV}$ and $\mathrm{C}-\mathrm{C}-\mathrm{O}$ at $286.5 \mathrm{eV}$. The main reason for this result is that polysulfone and PDA contain $\mathrm{C}-\mathrm{C}\left(\mathrm{sp}^{2}\right)$ (existing in benzene rings) and $\mathrm{C}-\mathrm{O}$. As shown in Figure 5(c), the carbon spectrum of $\mathrm{M}-\mathrm{GO}^{2}$ can be deconvoluted into three parts, namely a C-C $\left(\mathrm{sp}^{2}\right)$ peak at $284.6 \mathrm{eV}$, a C-OH peak at $285.9 \mathrm{eV}$, and a $\mathrm{C}-\mathrm{COOH}$ peak at $289 \mathrm{eV}$, attributable to $\mathrm{GO}$ on the $\mathrm{M}-\mathrm{GO}^{2}$ surface. The XPS results thus confirmed that GO had been successfully deposited on the membrane surface.

FTIR spectra of the PS, M-PDA, M-GO ${ }^{2}$, and M-GO ${ }^{4}$ are shown in Figure 6. It can be seen that M-PDA has a similar FTIR spectrum to 
Citation: Song X, Li Y, Zhao G, Lu Y, Li C, et al. (2018) A Novel Graphene Oxide Composite Nanofiltration Membrane with Excellent Performance and Antifouling Ability. J Membr Sci Technol 8: 184. doi:10.4172/2155-9589.1000184

Page 4 of 8
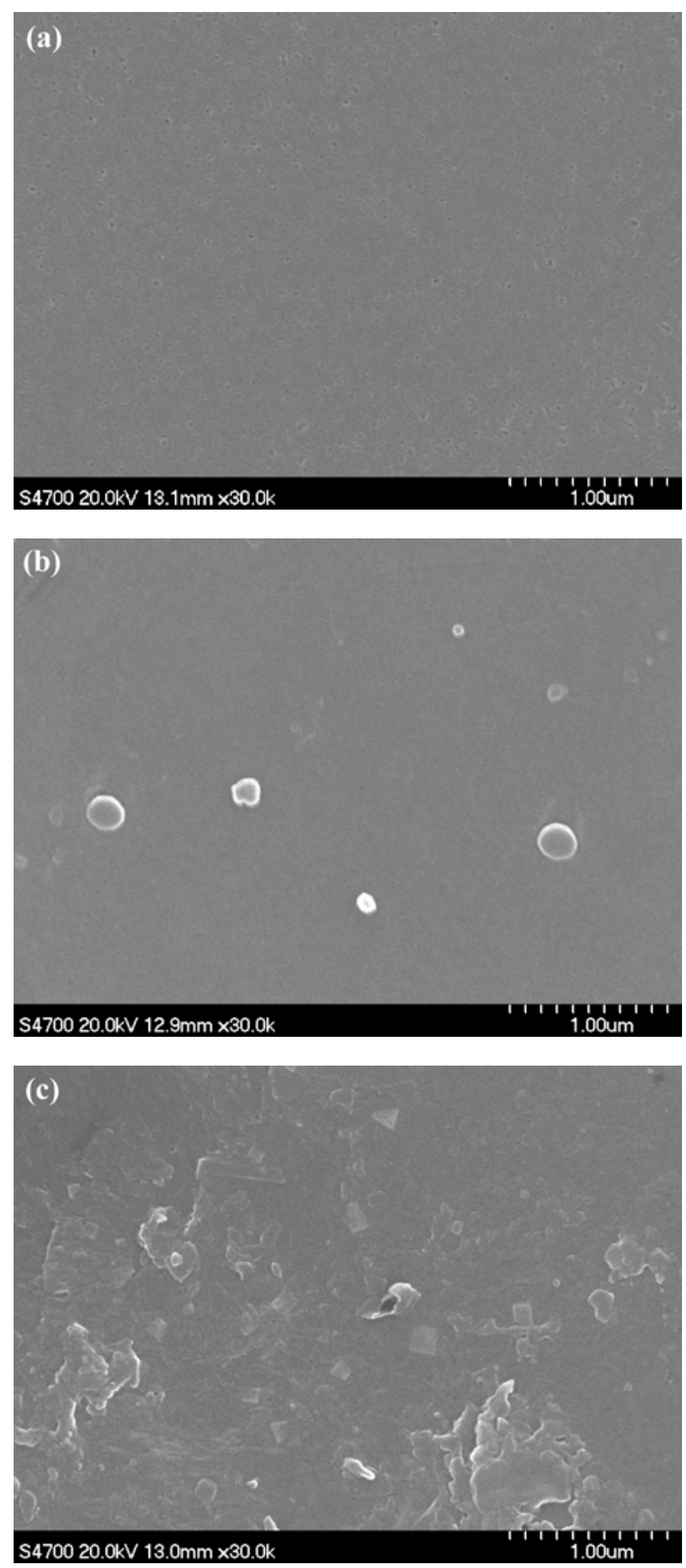

Figure 4: SEM images of different membrane during the assembly process: (a) PS membrane, (b) M-PDA, (c) M-GO

that of the PS membrane, indicating no new functional groups on its surface. In contrast to the spectra of the PS membrane and M-PDA, the FTIR spectra of M-GO ${ }^{2}$ and M-GO ${ }^{4}$ show a new peak at $1724 \mathrm{~cm}^{-1}$, attributable to the $\mathrm{C}=\mathrm{O}$ stretching vibrations of carboxyl, anhydride, and ester groups. Here, the carboxyl groups may have been present in GO or due to unreacted acyl chloride groups of TMC. Anhydride and ester groups may have resulted from reactions between TMC and PDA or GO. The intensity of the peak at $1724 \mathrm{~cm}^{-1}$ clearly increased with increasing number of GO layers, further corroborating that GO was successfully assembled on the membrane surface.
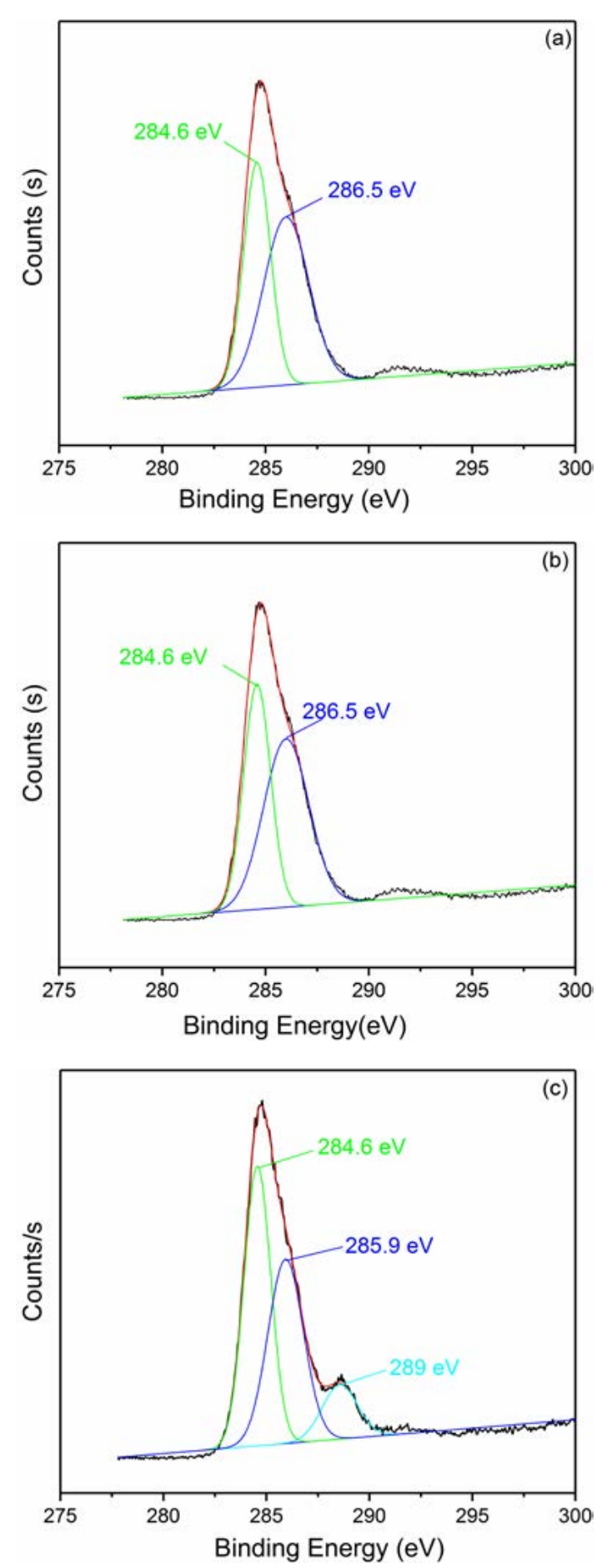

Figure 5: XPS spectra of different membrane surfaces: (a) Base membrane, (b) M-PDA, (c) M-GO2. 


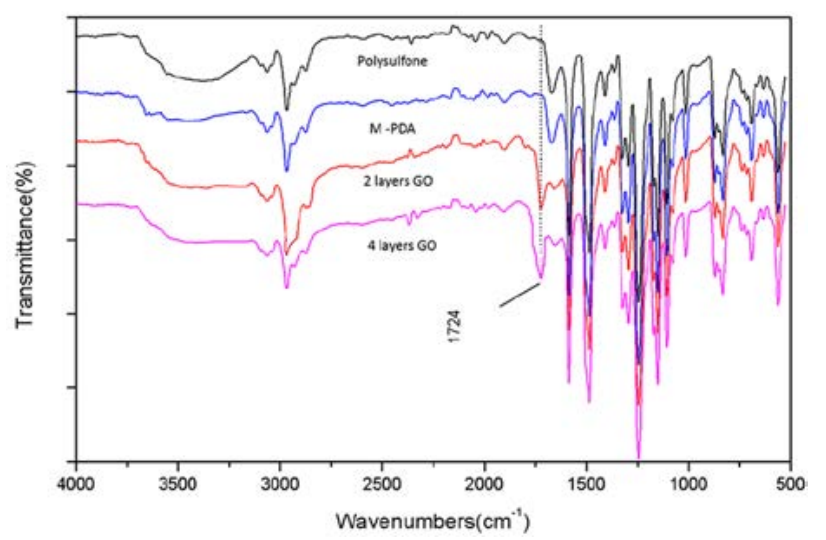

Figure 6: ATR-FTIR spectra of the PS membrane, M-PDA, M-GO², and M-GO4

To study the hydrophilicity of the membranes, we measured water contact angles at the surfaces of different membranes, namely PS, M-PDA, M-PDA 3 , M-TMC, M-GO ${ }^{2}, \mathrm{M}^{-G^{4}}$, and M-GO ${ }^{6}$. As can be seen from Figure 7, the contact angle on the hydrophobic PS membrane was $82^{\circ} \mathrm{C}$. This decreased to $70^{\circ} \mathrm{C}$ after modification with PDA, indicating that PDA increased the hydrophilicity of the membrane surface because of its hydrophilic catechol groups. In addition, $\mathrm{M}-\mathrm{PDA}$ showed a similar contact angle as $\mathrm{M}-\mathrm{PDA}^{3}$, indicating that the number of PDA composite layers has essentially no influence on the hydrophilicity of the membrane surface. The hydrophilicity of $\mathrm{M}-\mathrm{TMC}$, with a contact angle of $73^{\circ} \mathrm{C}$, is somewhat decreased due to the hydrophobic benzene ring. Moreover, the water contact angles of $\mathrm{M}-\mathrm{GO}^{2}, \mathrm{M}-\mathrm{GO}^{4}$, and $\mathrm{M}-\mathrm{GO}^{6}$ were all about $36^{\circ} \mathrm{C}$, indicating perfect hydrophilicity, which can be attributed to GO bearing large numbers of hydrophilic groups, including carboxyl, hydroxy, epoxy, and carbonyl. The contact-angle measurements thus indicated that PDA and GO can improve the hydrophilicity of the membrane surface to different degrees. The root average arithmetic roughnesses $(\mathrm{Ra})$ of the membrane surfaces were characterized by AFM. Three-dimensional AFM images of the PS membrane, M-PDA, and M-GO ${ }^{2}$ are shown in Figure 8(a-c). The AFM image of the PS membrane shows its Ra to be about $3.93 \pm 0.2 \mathrm{~nm}$; the surface is smooth and free from wrinkles. As can be seen from Figure 8 (b), the Ra of M-PDA (20.48 $\pm 0.1 \mathrm{~nm})$ was sharply increased due to aggregates of PDA with an average particle size of 30-200 nm, consistent with the SEM images. From Figure 8(c), it can be seen that the surface of $\mathrm{M}-\mathrm{GO}^{2}(\mathrm{Ra}=24.01 \pm 0.4 \mathrm{~nm})$ became even rougher due to irregular stacking of GO thereon. The AFM and SEM images of M-GO revealed GO sheets with an average particle size of 20-100 nm irregularly arranged on the membrane surface, which may have been due to the insufficient ultrasonication of GO or its inherently wrinkled structure. As a result, the water flux may have been somewhat improved due to the increased contact area between water and the membrane surface [30]. Zeta potential determination offers a means of studying the changing charge on the composite membrane surface $[35,36]$. The zeta potentials of the various membranes are plotted in Figure 9. It can be seen that the zeta potential of the PS membrane was close to zero, indicating no charge on the base surface. M-PDA has a negative charge of $-12.72 \mathrm{mV}$, which may be attributed to deprotonation of the catechol groups of PDA $[37,38]$. M-TMC and M-TMC ${ }^{2}$ had negative charges of -35.39 and $-101.1 \mathrm{mV}$, respectively, resulting from the carboxyl groups on the membrane surface. In humid air, the acid chloride groups on TMC may be hydrolyzed to carboxyl groups, imparting the membrane surface with negative charge. M-GO ${ }^{1}(-183.4 \mathrm{mV})$ clearly had a more

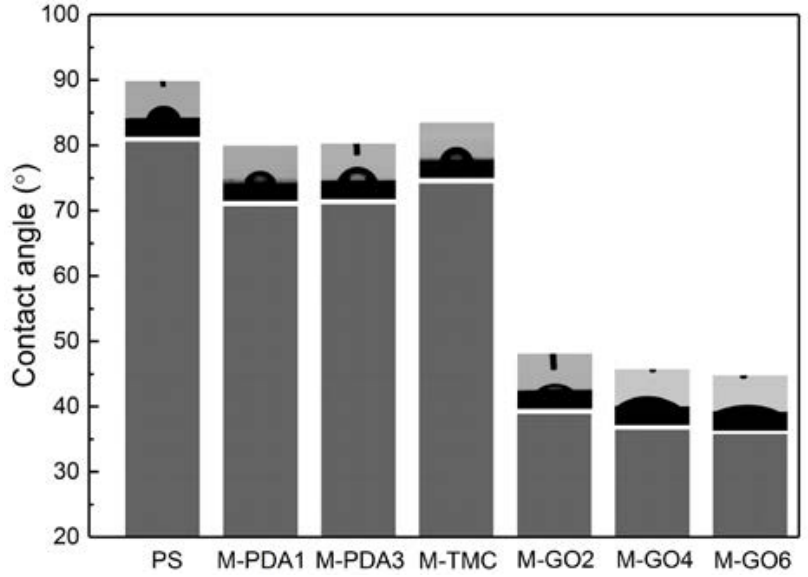

Figure 7: Contact-angle measurements of membranes during the assembly process.
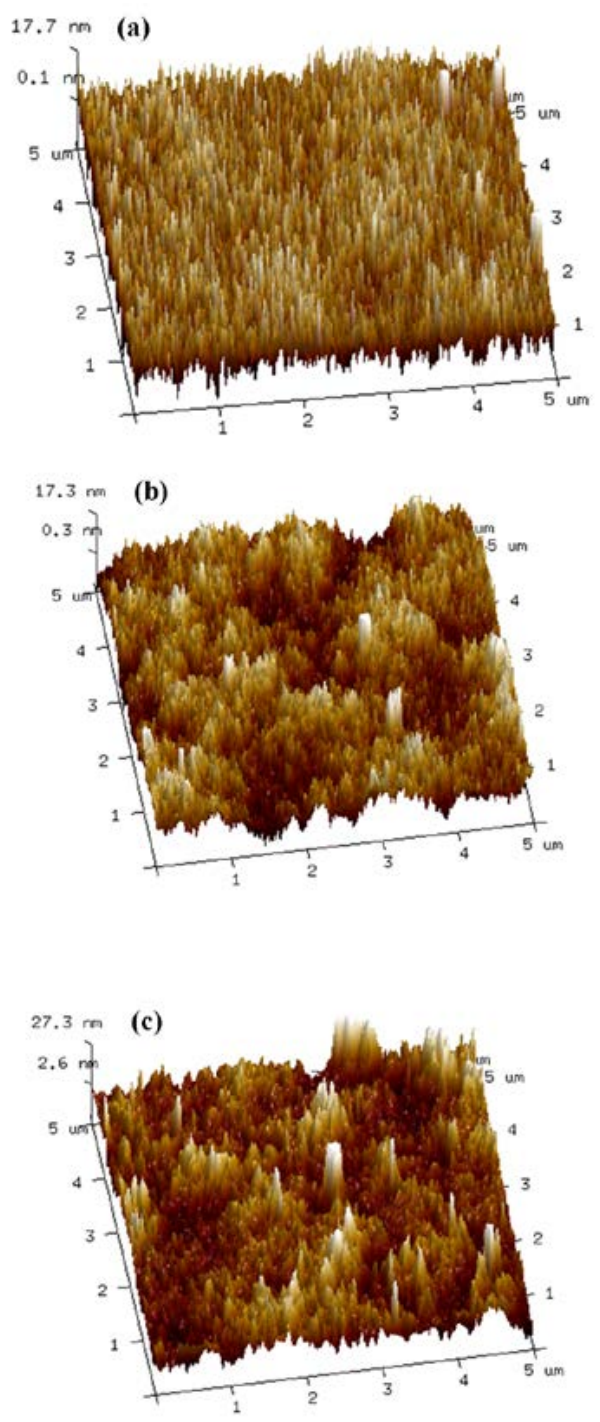

Figure 8: AFM images of membranes: (a) PS membrane, (b) M-PDA membrane, (c) M-GO2. 


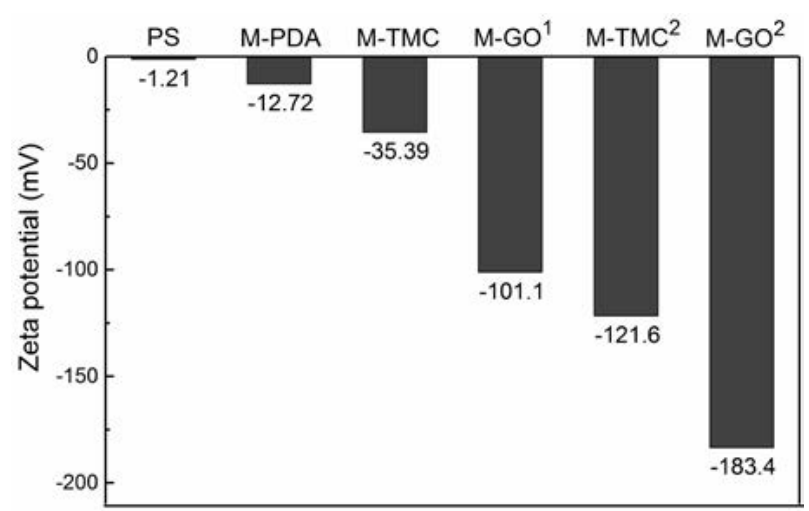

Figure 9: Changes in zeta potential on surface of the composite membranes.

negative zeta potential than M-TMC due to the carboxyl groups on GO deposited on the membrane surface. The same was true for $\mathrm{M}-\mathrm{TMC}^{2}$ $(-121.6 \mathrm{mV})$ and $\mathrm{M}-\mathrm{GO}^{2}(-183.4 \mathrm{mV})$. The zeta potentials of the GO composite membranes thus became more negative with increasing number of GO composite layers.

\section{Nanofiltration performance of $\mathrm{M}-\mathrm{GO}^{2}$}

Solutions of methyl blue, Congo red, acid magenta, methyl orange, and crystal violet, each at $100 \mathrm{ppm}$, were used as raw materials to determine the nanofiltration performances of $\mathrm{M}-\mathrm{GO}^{2}$ towards organic dyes of different molecular weights. The experimental results are shown in Figure 10. M-GO ${ }^{2}$ showed different rejections and water fluxes for the various organic dyes. With increasing molecular weight of the organic dyes, the rejection rate of $\mathrm{M}-\mathrm{GO}^{2}$ decreased. However, the water flux increased. For methyl blue with higher molecular weight, the rejection rate and permeation flux of the membrane were up to $98 \%$ and $70 \mathrm{kgm}$ ${ }^{2} \mathrm{~h}^{-1}$, respectively. For methyl orange, with lower molecular weight, the rejection rate and permeation flux of the membrane were up to $72 \%$ and $97 \mathrm{kgm}^{-2} \mathrm{~h}^{-1}$, respectively.

In order to study the nanofiltration performances of $\mathrm{M}-\mathrm{GO}^{2}$ towards anions with different valences, solutions of $\mathrm{NaCl}, \mathrm{Na}_{2} \mathrm{SO}_{4}$, and $\mathrm{Na}_{3} \mathrm{PO}_{4}$, each at $500 \mathrm{ppm}$, were used as raw materials to detect the rejection rates and permeation fluxes of $\mathrm{Cl}^{-}, \mathrm{SO}_{4}^{2-}$, and $\mathrm{PO}_{4}^{3-}$, respectively. The test results are shown in Table 1 . The rejection rates of the NF membrane towards $\mathrm{Cl}^{-}, \mathrm{SO}_{4}^{2-}$, and $\mathrm{PO}_{4}^{3-}$ were $48 \%, 86 \%$, and $92 \%$, respectively, with consistent permeation fluxes of about $120 \mathrm{kgm}$ ${ }^{2} \mathrm{~h}^{-1}$. The results of rejection rate of anion can be attributed to the zeta potential $(-183.4 \mathrm{mV})$ of the NF membrane surface. With adequate negative charge, the membrane could show good rejection capacity of anions, due to the strong coulombic repulsion. In fact, the rejection rate of anion is related to zeta potential, while, the permeation flux is related to membrane properties and the size of rejected ions. As the sizes of $\mathrm{Cl}$, $\mathrm{SO}_{4}^{2-}, \mathrm{PO}_{4}^{3-}(2-5 \AA)$ are much smaller than those of membrane pores, the permeation flux is mainly determined by the membrane properties. Therefore, permeation flux is almost unchanged when $\mathrm{Cl}, \mathrm{SO}_{4}^{2-}, \mathrm{PO}_{4}^{3-}$ are respectively rejected using the same membrane.

The anti-fouling ability of an NF membrane is one of the important indices to assess its performance. In this study, the anti-fouling ability of the NF membrane was tested by continuous operation for $12 \mathrm{hrs}$. The membrane was tainted with methyl blue (feed solution concentration $100 \mathrm{ppm}$ ) and then washed with clean water for $1 \mathrm{hr}$ at intervals of 3 hrs. Firstly, the original permeation flux of the membrane to methyl blue was tested and denoted as J0. Secondly, the membrane was washed for $1 \mathrm{hr}$ after $3 \mathrm{hrs}$ of operation; the permeation flux was recorded and denoted as J1. Similarly, J2, J3, and J4 were recorded after 6 hrs, 9 hrs, and 12 hrs respectively, of operation. Lastly, with methyl blue as the foulant, the water recovery rate (FRR) of the membrane was calculated according to equation (3):

$$
\operatorname{FRR}(\%)=\mathrm{J} 4 / \mathrm{J} 0
$$

The experimental results are shown in Figure 11, the red curve represents the variations of membrane flux with operation time while the black curve represents the variations of rejection rate with operation time. It is clearly noted that the rejection rate almost kept constant within the whole operation time. However, in the first three hours, the rapid adsorption of the methyl blue onto membrane surface would lead to the sharp decrease of membrane flux. After the adsorption

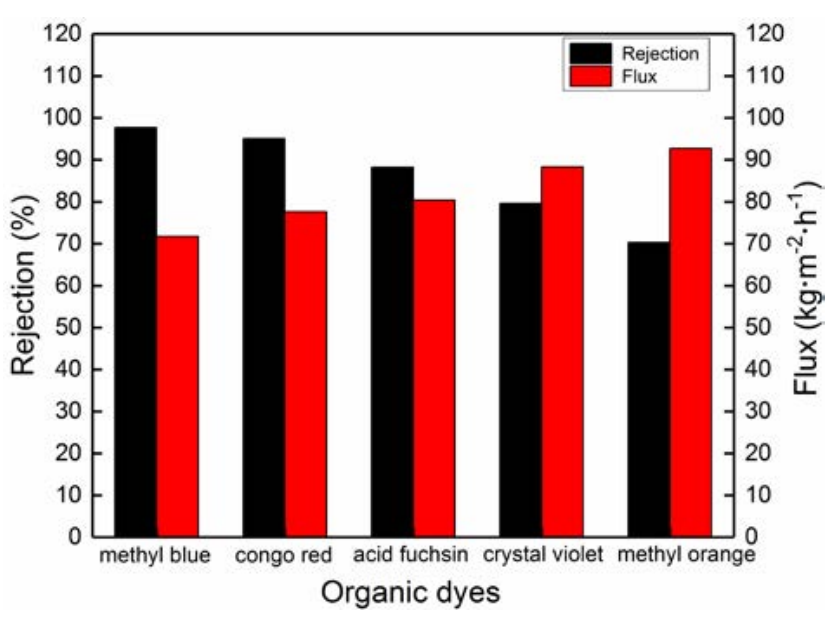

Figure 10: Nano-filtration performances of $\mathrm{M}-\mathrm{GO}^{2}$ towards organic dyes with different molecular weights.

\begin{tabular}{|c|c|c|}
\hline Anion & Rejection rate (\%) & Permeation flux $\left(\mathrm{kg} \cdot \mathrm{m}^{-2} \cdot \mathrm{h}^{-1}\right)$ \\
\hline $\mathrm{Cl}^{-}$ & 48.12 & 122.20 \\
\hline $\mathrm{SO}^{2-}$ & 86.47 & 121.33 \\
\hline $\mathrm{PO}^{3-}$ & 91.84 & 120.32 \\
\hline
\end{tabular}

Table 1: Nanofiltration performances of $\mathrm{M}-\mathrm{GO}^{2}$ towards $\mathrm{Cl}^{-}, \mathrm{SO}_{4}{ }^{2-}$, and $\mathrm{PO}_{4}{ }^{3-}$

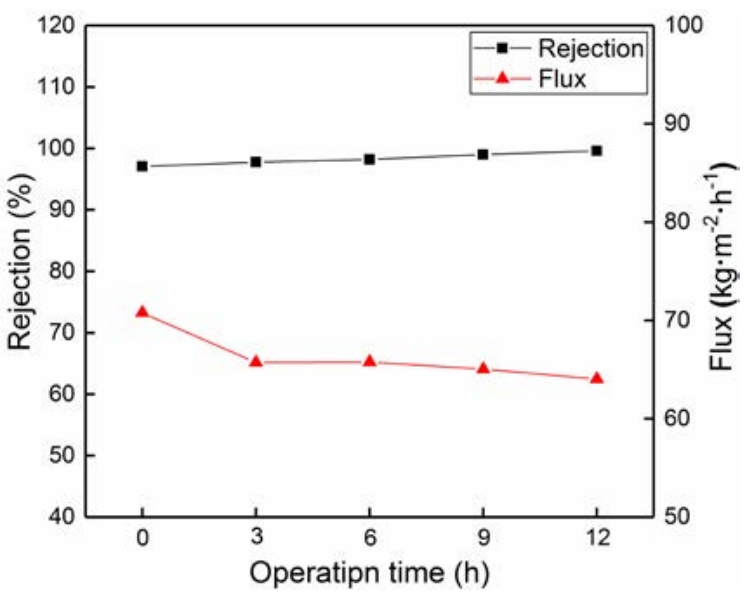

Figure 11: Anti-fouling ability of $\mathrm{M}-\mathrm{GO}^{2}$. 
Citation: Song X, Li Y, Zhao G, Lu Y, Li C, et al. (2018) A Novel Graphene Oxide Composite Nanofiltration Membrane with Excellent Performance and Antifouling Ability. J Membr Sci Technol 8: 184. doi:10.4172/2155-9589.1000184

reached saturation, the permeation flux remains essentially constant. The permeation flux of the membrane decreased from $70 \mathrm{kgm}^{-2} \mathrm{~h}^{-1}$ to $64 \mathrm{kgm}^{-2} \mathrm{~h}^{-1}$, and the FRR was about $90 \%$. In addition, the rejection rate of the membrane increased from $97 \%$ to $100 \%$. As GO has the ability for irreversible adsorption of methyl blue, the apertures of the membrane may diminish in size with increasing operation time, leading to the membrane showing increased rejection rate and decreased permeation flux.

\section{Conclusions}

$\mathrm{GO}$, as a single-atom-thick layer structure, readily accumulates into a two-dimensional structure with nanopores rich in hydrophilic groups. In this study, we have taken advantage of the specific structure of GO, depositing it on a PS membrane surface by an LBL assembly method. The GO was then cross-linked with TMC. As GO bears a large number of hydrophilic groups, the water contact angle of the prepared NF membrane surface was as low as $36^{\circ} \mathrm{C}$. Moreover, water can pass through the GO surface without any impediment, so that the membrane has high water flux. The prepared GO separation layer has a high negative zeta potential $(-183.4 \mathrm{mV})$ because of the carboxyl groups on GO, which can enhance the anti-fouling ability and stability of the NF membrane. Indeed, its FRR is up to $90 \%$.

\section{Acknowledgements}

This project was supported by the National Natural Science Foundation of China (Program No. 51473013 and Program No.51773012).

\section{References}

1. Jackson EA, Hillmyer MA (2010) Nanoporous membranes derived from block copolymers: from drug delivery to water filtration. Acs Nano 4: 3548-3553.

2. Dijkstra HP, Van Klink GPM, Van Koten G (2002) The use of ultra- and nanofiltration techniques in homogeneous catalyst recycling. Accounts of Chemical Research 35: 798-810.

3. Luo JQ, Ding, LH, Wan, YH, Paullier P, Jaffrin, MY (2010) Application of NFRDM (nanofiltration rotating disk membrane) module under extreme hydraulic conditions for the treatment of dairy wastewater. Chem Eng J 163: 307-316.

4. Chon K, Sarp S, Lee S, Lee JH, Lopez-Ramirez JA, et al. (2011) Evaluation of a membrane bioreactor and nanofiltration for municipal wastewater reclamation: Trace contaminant control and fouling mitigation. Desalination 272: 128-134.

5. Ellouze E, Tahri N, Ben Amar R (2012) Enhancement of textile wastewater treatment process using Nanofiltration. Desalination 286: 16-23.

6. Wei XY, Wang Z, Fan FH, Wang JX, Wang SC (2010) Advanced treatment of a complex pharmaceutical wastewater by nanofiltration: Membrane foulant identification and cleaning. Desalination 251: 167-175.

7. Vrijenhoek EM, Hong S, Elimelech M (2001) Influence of membrane surface properties on initial rate of colloidal fouling of reverse osmosis and nanofiltration membranes. J Mem Sci 188: 115-128.

8. Wei HL, Ren J, Han B, Xu L, Han LL, et al. (2013) Stability of polydopamine and poly (DOPA) melanin-like films on the surface of polymer membranes under strongly acidic and alkaline conditions. Colloids \& Surfaces B: Biointerfaces 110: $22-28$.

9. Schaubroeck D, Vercammen Y, Van Vaeck L, Vanderleyden E, Dubruel P, et al. (2014) Surface characterization and stability of an epoxy resin surface modified with polyamines grafted on polydopamine. Appl Surf Sci 303: 465-472.

10. Li B, Liu WP, Jiang ZY, Dong X, Wang BY, et al. (2009) Ultrathin and Stable Active Layer of Dense Composite Membrane Enabled by Poly (dopamine). Langmuir 25: 7368-7374

11. Burzio LA, Waite JH (2000) Cross-linking in adhesive quinoproteins: studies with model decapeptides. Biochem 39: 11147-11153.

12. Van der Leeden MC (2005) Are conformational changes, induced by osmotic pressure variations, the underlying mechanism of controlling the adhesive activity of mussel adhesive proteins? Langmuir 21: 11373-11379.
13. Miller DJ, Paul DR, Freeman BD (2014) An improved method for surface modification of porous water purification membranes. Polymer 55: 1375-1383.

14. Lv Y, Yang HC, Liang HQ, Wan LS, Xu ZK (2016) Novel nanofiltration membrane with ultrathin zirconia film as selective layer, Journal of Membrane Science. J Mem Sci 500: 265-271.

15. McCloskey BD, Park HB, Ju H, Rowe BW, Miller DJ, et al. (2010) Influence of polydopamine deposition conditions on pure water flux and foulant adhesion resistance of reverse osmosis, ultrafiltration, and microfiltration membranes. Polymer 51: 3472-3485.

16. Huang ZH, Zheng XY, Lv W, Wang M, Yang QH, et al. (2011) Adsorption of lead (II) ions from aqueous solution on low-temperature exfoliated graphene nanosheets. Langmuir: 27: 7558-7562.

17. Boukhvalov DW, Katsnelson MI, Son YW (2013) Origin of anomalous water permeation through graphene oxide membrane. Nano Letters 13: 3930-3935.

18. Wei N, Peng XS, Xu ZP (2014) Understanding water permeation in graphene oxide membranes. Acs Applied Materials \& Interfaces 6: 5877-5883.

19. Wei N, Peng XS, Xu ZP (2014) Breakdown of fast water transport in graphene oxides. Physical Review E Statistical Nonlinear \& Soft Matter Physics 89 012113

20. Ai LH, Zhang CY, Chen ZL (2011) Removal of methylene blue from aqueous solution by a solvothermal-synthesized graphene/magnetite composite. Journal of hazardous materials 192: 1515-1524.

21. Si Y, Samulski ET (2008) Synthesis of water soluble graphene. Nano Letters 8: $1679-1682$

22. Lee C, Wei XD, Kysar JW, Hone J (2008) Measurement of the Elastic Properties and Intrinsic Strength of Monolayer Graphene. Science 321: 385-388.

23. Li XL, Wang XR, Zhang L, Lee SW, Dai HJ (2008) Chemically Derived, Ultrasmooth Graphene Nanoribbon Semiconductors. Science 319: 1229-1232.

24. Li D, Kaner RB (2008) Graphene-Based Materials.Science 320: 1170-1171.

25. Xia SJ, Yao LJ, Zhao Y, Li NN, Zheng Y (2015) Preparation of graphene oxide modified polyamide thin film composite membranes with improved hydrophilicity for natural organic matter removal. Chemical Engineering Journal 280: 720-727.

26. Jeong HK, Lee YP, Lahaye RJWE, Park MH, An KH, et al. (2008) Evidence of Graphitic AB Stacking Order of Graphite Oxides, Journal of the American. Chemical Society 130: 1362-1366.

27. Cai WW, Piner RD, Stadermann FJ, Park S, Shaibat MA, et al. (2008) Synthesis and Solid-State NMR Structural Characterization of 13C-Labeled Graphite Oxide. Science 321: 1815-1817.

28. Shen HP, Wang NX, Ma K, Wang L, Chen G, et al. (2017) Tuning interlayer spacing of graphene oxide laminates with solvent green to enhance its nanofiltration performance. Journal of Membrane Science 527: 43-50.

29. Wang L, Wang NX, Li J, Li JW, Bian WW, et al. (2016) Layer-by-layer selfassembly of polycation/GO nanofiltration membrane with enhanced stability and fouling resistance. Separation and Purification Technology 160: 123-131.

30. Koinuma M, Ogata C, Kamei Y, Hatakeyama K, Tateishi H, et al. (2012) Photochemical engineering of graphene oxide nanosheets. The Journal of Physical Chemistry C 116: 19822-19827.

31. Cicero G, Grossman JC, Schwegler E, Gygi F, Galli G (2008) Water confined in nanotubes and between graphene sheets: A first principle study. Journal of the American Chemical Society 130: 1871-1878.

32. Gordillo MC, Marti J (2008) Structure of water adsorbed on a single graphene sheet. Physical Review B 78: 075432.

33. Gordillo MC, Marti J (2010) Water on graphene surfaces. Journal of Physics: Condensed Matter 22: 284111.

34. Gao SJ, Qin HL, Liu PP, Jin J (2015) SWCNT-intercalated GO ultrathin films for ultrafast separation of molecules. Journal of Materials Chemistry A 3: 66496654.

35. Adamczyk Z, Zembala M, Kolasinska M, Warszynski P (2007) Characterization of polyelectrolyte multilayers on mica and oxidized titanium by streaming potential and wetting angle measurements. Colloids and Surfaces A-Physicochemical and Engineering Aspects 302: 455-460. 
Citation: Song X, Li Y, Zhao G, Lu Y, Li C, et al. (2018) A Novel Graphene Oxide Composite Nanofiltration Membrane with Excellent Performance and Antifouling Ability. J Membr Sci Technol 8: 184. doi:10.4172/2155-9589.1000184

Page 8 of 8

36. Dejeu J, Lakard B, Fievet P, Lakard S (2009) Characterization of charge properties of an ultrafiltration membrane modified by surface grafting of poly (allylamine) hydrochloride. Journal of colloid and interface science 333: 335-340.

37. Yu B, Liu JX, Liu SJ, Zhou F (2010) Pdop layer exhibiting zwitter ionicity: a simple electrochemical interface for governing ion permeability. Chemical Communications 46: 5900-5902.

38. Kim KY, Yang E, Lee MY, Chae KJ, Kim CM, et al. (2014) Polydopamine coating effects on ultrafiltration membrane to enhance power density and mitigate biofouling of ultrafiltration microbial fuel cells (UF-MFCs).Water Research 54C: 62-68. 